\title{
An Effort to Understand What Factors Affect the Transfer Function of a Two-Winding Transformer
}

\author{
L. Satish, Senior Member, IEEE, and Subrat K. Sahoo, Student Member, IEEE
}

\begin{abstract}
The transfer function (TF) of a transformer winding (or its natural frequencies) is known to be dependent on many factors, like the type of winding excited, terminal configuration and type of secondary winding, arrangement of windings, clearances, tap and its positions, phase position, etc. Further, it was well established about half a century ago that the natural frequencies are influenced due to the complex interactions that exist between windings. Strangely, all publications dealing with TF until now have, so far, ignored this interaction. However, to date, what is not clearly understood is the extent of contribution from the individual windings, influence of the type of winding (disc/layer, interleaved, etc.), and effect of the terminal condition of the secondary winding in defining the shape of the resultant TF. This paper attempts to provide quantitative answers to many of these questions by considering a two-winding transformer. Further, it is demonstrated how knowledge about the TF of individual windings, when considered in isolation, could be utilized to identify the contributions from each winding to the pole structure of a two-winding TF. This feature is a novelty being reported for the first time, and it is conjectured that this finding could extend the diagnosing capability of TF method from fault detection to fault location. The results presented are based on extensive analytical calculations, circuit simulations, and experiments on model coils for different terminal conditions and winding types. It is believed that the contributions of this paper resolve some issues existing in $\mathrm{TF}$ interpretation and impart new impetus for further research.
\end{abstract}

Index Terms-Diagnostics, disc/layer and interleaved winding, interaction, natural frequencies, transfer function, transformers.

\section{INTRODUCTION}

$\mathbf{I}_{\mathrm{in}}$ NTRODUCTION of digital measurement techniques [1] in high-voltage impulse testing (in the mid 1980s) was singularly responsible for renewed research activity in this field, which was by then considered by many to have reached a plateau. The transfer function (TF) method, due to Malewski and Poulin [2], was a landmark outcome of this paradigm shift and involved the estimation of TF from time-domain data. In recent years, another version of it, namely the swept frequency approach (or FRA), has gained prominence. In the FRA method, TF is measured in the frequency domain, and problems like signal-to-noise ratio (SNR), frequency resolution, and aliasing encountered in the time-domain approach are naturally eliminated. TF can be obtained from either route and has been used in many applications. One important application among them is monitoring the mechanical integrity of transformer windings (during testing and while in service). It is known

Manuscript received August 18, 2003; revised January 21, 2004. Paper no. TPWRD-00433-2003.

The authors are with the Department of High Voltage Engineering, Indian Institute of Science, Bangalore 560012, India.

Digital Object Identifier 10.1109/TPWRD.2004.833901 that mechanical deformations arise mainly due to short-circuit forces, unskilled handling, and rough transportation. Information related to winding deformation is embedded in the TF. Hence, to ensure accurate diagnosis, a correct interpretation of TF should obviously be the first step. Therefore, it is essential that all factors and/or interactions that affect TF must be taken into account. Unless this matter is addressed, acceptance of TF as a diagnostic tool in such applications will remain questionable.

Since the introduction of the TF approach, several publications have been written about various aspects of this method [3]-[6]. However, in all of these publications, TF shape and its structure have been analyzed, considering only the tested winding and neglecting all other influences. While interpreting $\mathrm{TF}$, ignoring these naturally occurring interactions would lead to serious errors. This is despite the fact that the existence of these interactions and their effects on natural frequencies has been established almost half a century ago, due to the pioneering work of Abetti et al. [7], [8]. Until now, only an awareness of this interaction existed, and this has now proved to be insufficient, if progress with TF has to be achieved. In fact, answers to questions like what and how much is the contribution from each winding, whether there is any effect due to type of windings involved, what is the influence of terminal conditions of untested windings, etc., toward shaping resultant TF are, as yet, not fully established. So, an investigation about these matters becomes essential which, in turn, would enable a more accurate interpretation of TF. Hence, it forms the subject matter of this work.

Another aspect closely linked with the subject matter of this paper is the necessity to extract information embedded in TF. This information could be used for enhancing interpretation. Somehow, this has not attracted adequate attention and so, a concern about it has been expressed in recent times. In [9], an attempt is made to show how the location of fault is correlated to changes in TF shape. Here, it is mentioned that "TF as a fault diagnosis tool can become viable, only with an improvement in the ability of TF interpretation." Being aware of such a necessity, Satish and Jain in [10] present analytical proof to explain why TF structure of an interleaved winding is shaped so differently and what causes it to differ from the $\mathrm{TF}$ of a disc/layer winding. Implications of these findings to diagnostics are explained. Hence, this happens to be another reason for undertaking this investigation.

\section{PRoblem Definition}

TF gives a pictorial visualization of the arrangement of poles and zeros of a transformer winding. It is often assumed that TF shape depends only on the type of winding that is excited, 
namely, continuous-disc, interleaved-disc, etc. A study of TF in literature reveals that it is not always the case, for example, the TF of a single untanked transformer winding, when examined alone, reveals certain characteristic features dependent only on the type of winding. However, when TF of the transformer as a whole is examined (with all windings in place and usual terminal conditions), surprisingly, the same TF characteristics are often not observed, even though the same winding is energized.

It is well documented that both continuous-disc and layer type of windings are typically characterized by a sequence of well-defined peaks and troughs, with gradually decaying magnitude, and exist up to about 1.0 MHz [6], [9], [10]. These salient features, normally associated with a disk/layer winding, are observed only when the winding is tested in isolation. Similarly, an interleaved winding is known to typically have only a few low-frequency poles (when considered alone) and, in fact, this facet is its discriminating feature. However, when TF of a transformer with disc/layer winding or interleaved winding is measured, it is observed that the salient features expected from the winding under consideration are not always ensuing. The crucial question that now arises is the following.

- Why does the TF of a transformer not always reveal the structure expected of the particular type of winding, and what is the cause for the deviation?

- What is not apparent is why, in some cases, an influence on TF is observed, while in some others, there is no appreciable influence due to the remaining windings.

In the past, when such discrepancies were encountered, no credible justification was put forward. Therefore, what essentially needs to be quantified is to what extent do each of the windings influence the resultant TF, what is the influence, if any, of the type of windings, effect of terminal condition of remaining windings, and under what circumstances is the influence of winding interaction significant, etc. toward reshaping the resultant TF. Answers to the above would provide clues to examine the following principal questions that usually arise when a TF is examined.

- With a transformer winding being a complex coupled network, is it possible to identify what winding the observed natural frequencies or poles belong to? Moreover, would such an allocation at all be possible?

- A deviation in two subsequently measured TF usually signifies a fault, when all other test conditions remain unaltered. So, is it possible to correlate observed deviation and the winding associated with the fault?

- With regard to increasing fault detection sensitivity using TF method, which secondary winding terminal configuration would be most appropriate for conducting the lowvoltage impulse (LVI)/swept frequency test?

The objective of this paper is to find quantitative answers to these often-asked questions. An effort in this direction is desirable, as it will enable a more objective and meaningful assessment of TF.

\section{AdOPTED MODEL AND SOLUTION}

As the goal of the present investigation involved the study of neutral current and TF, a completely coupled ladder network

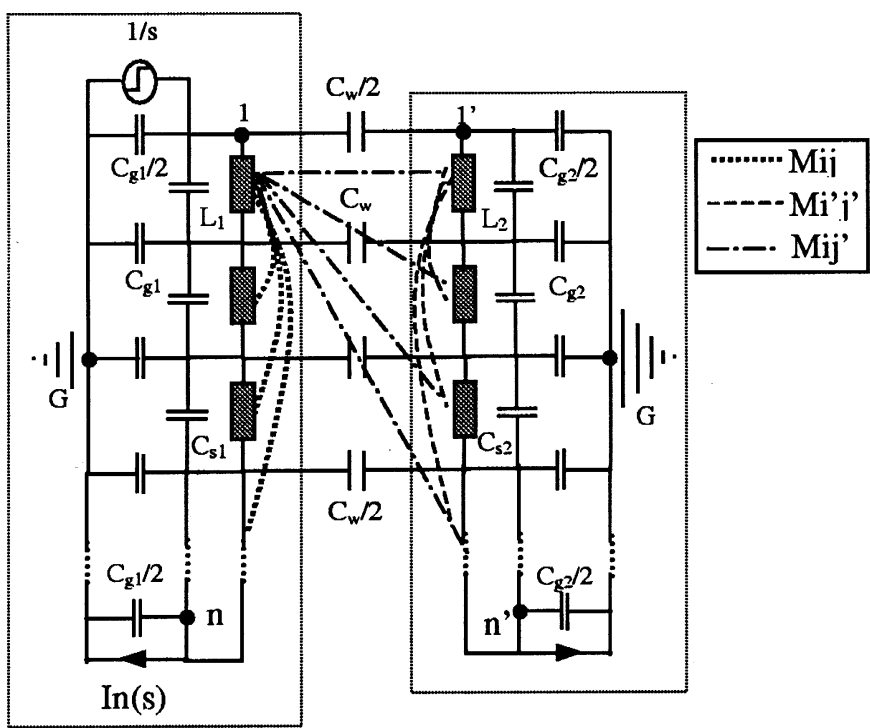

Primary

Secondary

Fig. 1. Equivalent circuit of two-winding transformer.

circuit representation was considered adequate. It has widely been used in the past and is also known to accurately model all subtle aspects of the neutral current response due to full and chopped lightning impulses. In addition, this representation readily permits analytical investigation (using symbolic computation), computation of time-domain responses using circuit simulation software (PSPICE), and also construction of a winding model for experimental verification.

In this study, each winding was represented by a coupled ladder network circuit comprising of series capacitance $\left(C_{s 1}, C_{s 2}\right)$, series inductance $\left(L_{1}, L_{2}\right)$, shunt capacitance $\left(C_{g 1}, C_{g 2}\right)$, interwinding capacitance $\left(C_{w}\right)$, all mutual inductances between each section of a winding ( $M i j$ and $M i^{\prime} j^{\prime}$ for primary and secondary, respectively), and all mutual inductances between the two windings $\left(M i j^{\prime}\right)$, as shown in Fig. 1. Loss in the winding was modeled by a lumped resistance $\left(r_{1}, r_{2}\right)$ in series with series inductance in both windings. The short-circuited condition of the secondary winding was simulated by connecting the secondary line terminal (i.e., node $1^{\prime}$ to ground). In all analytical calculations, a neutral terminal of both the primary and secondary winding was always solidly grounded. However, in PSPICE simulations, the neutral of primary winding was connected to the ground via a small resistance to permit neutral current computation, while in case of secondary winding, pertinent nodes are eliminated.

The first part of the study consisted of analytically solving the circuit (in Fig. 1) to determine neutral current $I_{n}(s)$ in $s$-domain for a step input using nodal analysis method. The method described in [10] for a single winding was extended to include two coupled windings. The step excitation was a natural choice as it simplifies computations, and in addition, poles and zeros of $I_{n}(s)$ are also the poles and zeros of TF, except for an additional zero at origin, because $\mathrm{TF}=s * I_{n}(s)$. The program was coded in MAPLE and directly outputs poles and zeros (in Mega-neper $\pm \mathrm{jMega}-\mathrm{rad} / \mathrm{s}$ ) of TF. It takes about $150 \mathrm{~s}$ (on a P4, 800-MHz, 256-MB RAM) to solve a fully coupled network 
(with loss) with five sections each in primary and secondary. It must be mentioned here that the analytical solution for networks beyond eight sections per winding was not achievable (memory and related errors were encountered), with the existing formulation. So an alternative solution suitable for any number of sections per winding has been developed and shall be reported separately.

In the second part of the study, the circuit in Fig. 1 was solved in PSPICE using "LIN AC SWEEP ANALYSIS" option and yields TF directly in the frequency domain. This step happens to be a validation of analytical formulation and program code developed. Simulations were repeated for different values of $C_{s 1}$ (to simulate conditions of disk and interleaved winding) and for different secondary winding terminal conditions, viz. open and short circuit (neutral of secondary was always grounded). Naturally, the final step was to verify the theoretical findings by suitable experiments.

\section{BASIS FOR TF INTERPRETATION}

The underlying principle of this study initially involves the examination of primary and secondary windings separately for its individual TF behavior. Thereafter, this information is used to interpret $\mathrm{TF}$ characteristics of the transformer as a whole (i.e., when these two windings are put together in place). In other words, the TF (i.e., poles and zeros) of each winding was initially determined (without any external influence) and thereafter, the resultant TF of the two-winding transformer (poles and zeros) was examined, based on TF information of individual windings. This approach of TF interpretation is a new method being introduced for the first time, and it is not difficult to visualize how it could be implemented in practice. It essentially involves, soon after the winding is manufactured and before it is placed in the core assembly, measurement of the individual TF (without influence of the other winding). For this, the ground-plane condition due to the core/tank has to be simulated using metallic screens.

Although this means of analysis turns out to be useful (as will be shown), it must be mentioned that there arises a minor discrepancy as far as one secondary winding node is concerned. That is, the secondary line-end node $\left(1^{\prime}\right)$ to which input excitation is fed when determining its individual TF would become an independent node when open-circuited secondary is considered in the two-winding case and, hence, will result in an additional pole in the resultant TF. In the secondary short-circuited case, such an additional pole will, for obvious reasons, not arise. Therefore, when a single winding is represented as a $N$-section network, it will possess $(N-1)$ poles, a two-winding transformer with each winding represented as a $N$-section network will possess $2(N-1)$ and $(2 N-1)$ poles, when the secondary is short-circuited and open-circuited, respectively. This point must particularly be noted during discussion of the results on open-circuited secondary.

\section{Simulation Results}

In order to explain how the TF can be interpreted by the proposed method, initially results for a simple two-winding transformer, with each winding represented as a five-section network
TABLE I

Mutual InduCtanCES: $M i j, M i^{\prime} j^{\prime}$, AND $M i j^{\prime}$ IN MICROHENRYS

\begin{tabular}{|c|c|}
\hline$M i j$ & $\begin{array}{l}M_{1-2}=110.75, \quad M_{1-3}=73.97, \quad M_{1-4}=54.67, \quad M_{1-5}=42, \quad M_{1-} \\
6=33.15, M_{1-7}=26.7, M_{1-8}=21.45, M_{1-9}=17.6, M_{1-10}=14.8\end{array}$ \\
\hline$M i^{\prime} j^{\prime}$ & $\begin{array}{l}\mathrm{M}_{1^{\prime}-2^{\prime}}=36, \mathrm{M}_{1^{\prime}-3^{\prime}}=25, \mathrm{M}_{1^{\prime}-4^{\prime}}=18, \mathrm{M}_{1^{\prime}-5^{\prime}}=14, \mathrm{M}_{1^{\prime}-6^{\prime}}=10, \mathrm{M}_{1^{\prime}-} \\
7^{\prime}=8, \mathrm{M}_{1^{\prime}-8^{\prime}}=6.3, \mathrm{M}_{1^{\prime}-9^{\prime}}=5, \mathrm{M}_{1^{\prime}-10^{\prime}=4.25}\end{array}$ \\
\hline$M i j$ & $\begin{array}{l}\mathrm{M}_{1-1}=54.5, \mathrm{M}_{1-2}=52, \mathrm{M}_{1-3}=42, \mathrm{M}_{1-4}=33, \mathrm{M}_{1-5},=25.5, \mathrm{M}_{1-} \\
6^{\prime}=20, \mathrm{M}_{1-7^{\prime}}=17.15, \mathrm{M}_{1-8}=14.15, \mathrm{M}_{1-9}=11.5, \mathrm{M}_{1-10^{\prime}}=10\end{array}$ \\
\hline
\end{tabular}

(with loss) will be discussed. However, when experimental results are discussed, the simulation results of a ten-section network representation (each winding with loss) will be included. Before discussing simulation results, it is appropriate to mention all circuit parameters used, so that they could be independently verified by other researchers.

1) Each winding is represented as a five-section equivalent circuit as in Fig. 1. The values of self and mutual inductance of primary and secondary and mutual inductance between the primary and secondary were measured (using an L-C-R bridge) for the model experimental coils (described later), and the same values have been used in simulations as well. A constant effective resistance of 1.2 and $0.5 \Omega$ per section is considered in primary and secondary, respectively (this damping increases with frequency) and is as per the low-frequency measurement on the experimental coils. The primary and secondary winding self-inductance per section are 180 and $65 \mu \mathrm{H}$, respectively. Table I gives all of the mutual inductances involved between sections, and due to symmetry, remaining values can be determined.

2) The total shunt capacitance of the primary winding was taken as $3 \mathrm{nF}$ and that for secondary winding was fixed at twice this value (i.e., at $6 \mathrm{nF}$ in all simulations).

3) The total capacitance between the two windings was taken as $5 \mathrm{nF}$ (i.e., about twice the total shunt capacitance of primary winding to ground).

4) By choosing the appropriate values of series capacitance $\left(C_{s 1}\right)$, the winding condition starting from disc/layer up to interleaved winding can be modeled. The term interleaved and disc/layer are used only to signify high and low series capacitance, respectively. Let " $\alpha$ " be defined as the square root of the ratio of total shunt capacitance to total series capacitance of a winding, and let $\alpha_{p}$ and $\alpha_{s}$ denote primary and secondary winding $\alpha$, respectively.

Keeping $\alpha_{s}$ constant at $15, \alpha_{p}$ was gradually varied from 1.414 to 15 (in all 12 values), and TF was examined for both secondary open and short-circuit conditions. Although in practice, $\alpha$ for interleaved windings is about 3-4, a lower value was chosen to enable a complete understanding of winding interactions, when $\alpha_{p}$ is varied. For all of these cases, analytical results as well as PSPICE results were obtained. Careful inspection and consolidation of all changes occurring in TF gathered from these simulations, assists in compiling a knowledge base that would finally aid in identification of TF poles and the windings to which they belong to. However, due to brevity of space, results of only a few representative cases ( $\alpha_{p}$ corresponding to low, medium, high, very high, and equal to $\alpha_{s}$ ) will be discussed (for details, see [11]). 

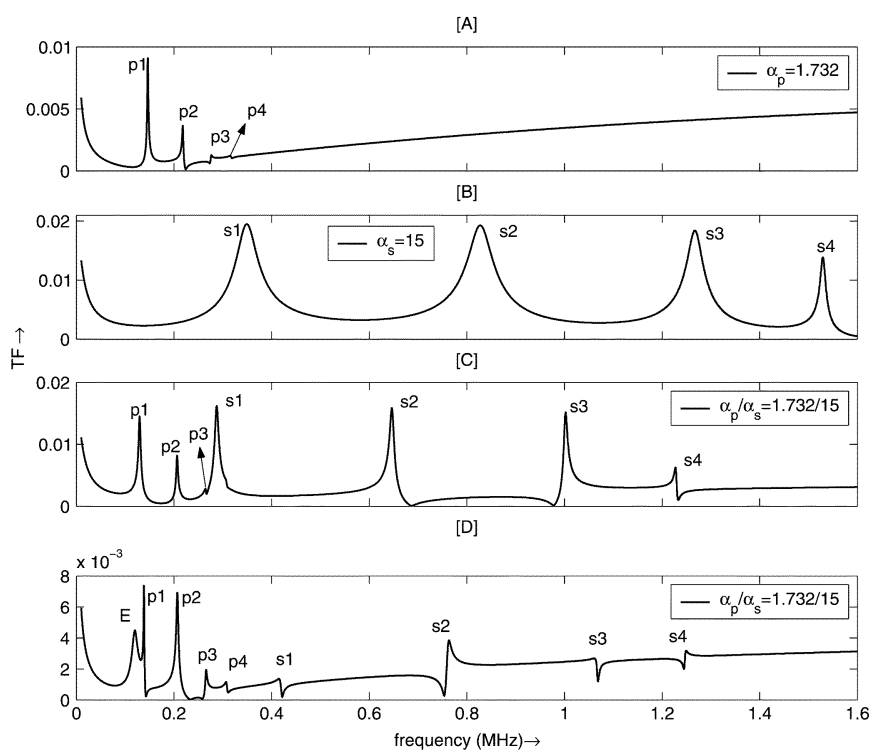

Fig. 2. TF from swept frequency analysis. Case $1: \alpha_{p} / \alpha_{s}=1.732 / 15$. (a) Primary alone. (b) Secondary alone. (c) Two windings: secondary shorted. (d) Secondary open.

\section{A. Case 1: $\alpha_{p} / \alpha_{s}=1.732 / 15$}

1) Secondary Short-Circuited: Usually in large capacity, high-voltage (HV) two-winding transformers, the HV winding is interleaved (fully or partially) and low-voltage (LV) winding is of disc/layer type. To simulate this condition, let $\alpha_{p} / \alpha_{s}=1.732 / 15$. The TF obtained from PSPICE ("LIN AC SWEEP ANALYSIS") by considering one winding at a time is shown in subplots A and B of Fig. 2. The typical characteristics of interleaved and disc winding (when examined alone) are evident in these subplots, viz. interleaved winding has only a few poles, while disc-type winding has many poles (four poles for a five- section network) with well-defined peaks and troughs. Poles in TF are labeled as p1, p2, p3, etc. and s1, s2, s3, etc. to distinguish between primary and secondary, respectively.

Table II gives analytically computed poles and zeros of TF for each winding considered separately, and also for both conditions of the two winding case. In table, the nearest poles and zeros have been paired (by comparing imaginary parts of pole and zero) and arranged in ascending order. For the two-winding case, pole-zero contributions arising from the individual windings have been separated after a careful study of TF plot and pole-zero values. Once a trend in changes occurring in TF is established, the task of assigning the winding from which a pole arises becomes much easier. Last, the table is helpful in identifying pole-zero cancellations occurring in TF, and these are shown as shaded. Due to page-length restrictions, the table for only the first two cases was included.

TF for the two-winding case, with the secondary winding shorted, is shown in Fig. 2, subplot C. From a combined study of subplots A, B, C, and Table II, the following points can be observed.

- In the two-winding TF, poles corresponding to the primary and secondary undergo left shift with respect to the position they occupied when winding was considered alone. The shift of secondary poles is greater compared to primary poles (this being maximum, for highest frequency secondary pole).
TABLE II

Analytically Computed TF POLESANd Zeros. CASE 1: $\alpha_{p} / \alpha_{s}=1.732 / 15$ (Pole Zero CANCELlations ARE SHOWN AS SHADED)

\begin{tabular}{|c|c|c|c|c|c|c|}
\hline & \multirow{2}{*}{\multicolumn{2}{|c|}{ Individual winding }} & \multicolumn{4}{|c|}{ Both the windings } \\
\hline & & & \multicolumn{2}{|c|}{ Secondary (Short) } & \multicolumn{2}{|c|}{ Secondary (Open) } \\
\hline & Poles & Zeros & Poles & Zeros & Poles & Zeros \\
\hline \multirow{7}{*}{ 胥 } & -0.0024 & & & & -0.0024 & \\
\hline & \multirow{2}{*}{$\begin{array}{l}-0.0033 \\
\pm 0.9194 \mathrm{i}\end{array}$} & $\begin{array}{c}0.1818 \\
\pm 0.8168 \mathrm{i}\end{array}$ & \multirow{2}{*}{$\begin{array}{c}-0.0036 \\
\pm 0.8151 \mathrm{i}\end{array}$} & $\begin{array}{c}0.2457 \\
\pm 1.1070 \mathrm{i}\end{array}$ & \multirow{2}{*}{$\begin{array}{c}-0.0035 \\
\pm 0.8724 \mathrm{i}\end{array}$} & \multirow{2}{*}{$\begin{array}{c}-0.0046 \\
\pm 0.8961 \mathrm{i}\end{array}$} \\
\hline & & $\begin{array}{c}-0.1855 \\
\pm 0.8171 \mathrm{i}\end{array}$ & & $\begin{array}{c}-0.2525 \\
\pm 1.1099 \mathrm{i}\end{array}$ & & \\
\hline & \multirow{2}{*}{$\begin{array}{c}-0.0061 \\
\pm 1.3708 \mathrm{i}\end{array}$} & \multirow{2}{*}{$\begin{array}{c}-0.0051 \\
\pm 1.4070 \mathrm{i}\end{array}$} & \multirow{2}{*}{$\begin{array}{c}-0.0063 \\
\pm 1.2962 \mathrm{i}\end{array}$} & $\begin{array}{c}-0.4787 \\
\pm 1.3320 \mathrm{i}\end{array}$ & \multirow{2}{*}{$\begin{array}{c}-0.0063 \\
\pm 1.3007 \mathrm{i}\end{array}$} & \multirow{2}{*}{$\begin{array}{c}-0.0063 \\
\pm 1.4688 \mathrm{i}\end{array}$} \\
\hline & & & & $\begin{array}{c}0.4656 \\
\pm 1.3342 \mathrm{i}\end{array}$ & & \\
\hline & $\begin{array}{c}-0.0094 \\
\pm 1.7312 \mathrm{i}\end{array}$ & $\begin{array}{r}-0.0078 \\
\pm 1.7243 \mathrm{i}\end{array}$ & $\begin{array}{c}-0.0093 \\
\pm 1.6680 \mathrm{i}\end{array}$ & $\begin{array}{r}-0.0088 \\
\pm 1.6731 \mathrm{i}\end{array}$ & $\begin{array}{c}-0.0094 \\
\pm 1.6682 \mathrm{i}\end{array}$ & $\begin{array}{r}-0.0096 \\
\pm 1.6238 \mathrm{i}\end{array}$ \\
\hline & $\begin{array}{c}-0.0123 \\
\pm 1.9924 \mathrm{i}\end{array}$ & $\begin{array}{r}-0.0102 \\
\pm 1.9946 \mathrm{i}\end{array}$ & $\begin{array}{c}-0.0122 \\
\pm 1.9352 \mathrm{i}\end{array}$ & $\begin{array}{r}-0.01247 \\
\pm 1.9377 \mathrm{i}\end{array}$ & $\begin{array}{c}-0.0122 \\
\pm 1.9349 \mathrm{i}\end{array}$ & $\begin{array}{r}-0.0123 \\
\pm 1.9471 \mathrm{i} \\
\end{array}$ \\
\hline \multirow{8}{*}{ 胥 } & \multirow{3}{*}{-0.0029} & -1.3795 & \multirow{2}{*}{$\begin{array}{l}-.0015 \\
-0.0109\end{array}$} & \multirow{2}{*}{-0.0029} & \multirow{2}{*}{$\begin{array}{c}-0.0048 \\
\pm 0.7501 \mathrm{i}\end{array}$} & $\begin{array}{c}0.3146 \\
\pm 0.7113 \mathrm{i}\end{array}$ \\
\hline & & 1.3782 & & & & $\begin{array}{l}-0.3195 \\
\pm 0.7116 \mathrm{i}\end{array}$ \\
\hline & & $\begin{array}{l}-287.39 \\
287.382\end{array}$ & $\begin{array}{c}-0.0049 \\
\pm 1.8030 \mathrm{i}\end{array}$ & & $\begin{array}{c}-0.0052 \\
\pm 2.6289 \mathrm{i}\end{array}$ & $\begin{array}{r}-0.0049 \\
\pm 2.6511 \mathrm{i}\end{array}$ \\
\hline & $\begin{array}{c}-0.0039 \\
\pm 2.1827 \mathrm{i}\end{array}$ & & $\begin{array}{c}-0.0068 \\
\pm 4.0523 \mathrm{i}\end{array}$ & $\begin{array}{c}-0.0070 \\
\pm 4.3133 \mathrm{i}\end{array}$ & $\begin{array}{c}-0.0069 \\
\pm 4.7683 \mathrm{i}\end{array}$ & $\begin{array}{r}-0.0070 \\
\pm 4.7330 \mathrm{i}\end{array}$ \\
\hline & $\begin{array}{r}-0.0067 \\
\pm 5.1776 \mathrm{i}\end{array}$ & & $\begin{array}{c}-0.0094 \\
\pm 6.2844 \mathrm{i}\end{array}$ & $\begin{array}{c}-0.0094 \\
\pm 6.1419 \mathrm{i}\end{array}$ & $\begin{array}{c}-0.0097 \\
\pm 6.7009 \mathrm{i}\end{array}$ & $\begin{array}{r}-0.0093 \\
\pm 6.7135 \mathrm{i}\end{array}$ \\
\hline & \multirow{2}{*}{$\begin{array}{c}-0.0094 \\
\pm 7.9448 \mathrm{i}\end{array}$} & $\begin{array}{c}-4.6505 \\
\pm 7.0212 \mathrm{i}\end{array}$ & \multirow{2}{*}{$\begin{array}{c}-0.0108 \\
\pm 7.7212 \mathrm{i}\end{array}$} & \multirow{2}{*}{$\begin{array}{r}-0.0109 \\
\pm 7.7492 \mathrm{i}\end{array}$} & \multirow{2}{*}{$\begin{array}{c}-0.0108 \\
\pm 7.8353 \mathrm{i}\end{array}$} & \multirow{2}{*}{$\begin{array}{c}-0.0108 \\
\pm 7.8319 \mathrm{i}\end{array}$} \\
\hline & & $\begin{array}{c}4.6194 \\
\pm 7.0454 \mathrm{i}\end{array}$ & & & & \\
\hline & $\begin{array}{c}-0.0107 \\
\pm 9.6077 \mathrm{i}\end{array}$ & $\begin{array}{c}-0.0235 \\
\pm 10.808 \mathrm{i}\end{array}$ & & & & \\
\hline
\end{tabular}

- Notwithstanding this varying degree of left shift of poles, an inspection of resultant TF reveals that the ratio of distance between any two adjacent primary poles existing in the single winding case remains more or less similar in the two-winding TF as well (termed distance rule) for most values of $\alpha_{p}$. This is an important feature and proves useful in the identification of poles and the corresponding winding to which they belong to. (When distance rule is not followed, the trend of pole shifts in the immediate lower and higher value of $\alpha_{p}$ can be used to determine contributions emerging from individual windings.)

- Using the above two points and numerical values of pole-zero in Table II as input, pole contributions from each winding have been manually identified for the two-winding TF and is shown in subplot $\mathrm{C}$ of Fig. 2.

- Poles p3 and p4 in subplot A almost cancel out and so are barely visible (shown as shaded in the table). A similar trend is observed, although the extent of cancellation is less, even in the two-winding TF as well. Also, here separation distance between poles and zeros is observed to marginally increase. This is one reason why the pole amplitudes of $\mathrm{p} 1$ to $\mathrm{p} 4$ are, in general, higher in the two-winding TF compared to that in TF of a single winding.

- On the contrary, secondary winding zeros occupy newer positions such that compared to its position in the single winding condition, they are closer to their corresponding 
poles, and are shaded in Table II. Such pole-zero pairs manifest themselves as sharp transitions in TF (e.g., s4 in subplot $\mathrm{C}$ (when distance between pole and zero is less than $0.05 \mathrm{i}$, it is treated as cancelled). These finer aspects are noticeable only in theoretical computations, but will remain undetected during measurements.

Here, the TF of primary (interleaved) winding with secondary (disc/layer) winding shorted, resembles a disc/layer type of winding containing five to six dominant poles, with well-defined peaks and troughs. So, merely by an inspection of the two-winding TF alone, it would be inappropriate to draw conclusions regarding the type of tested winding.

2) Secondary Open-Circuited: Results for the secondary open-circuited case are shown in Fig. 2, subplot D. As already mentioned, there will arise an extra pole in this case, and it is labeled as "E" in subplot D. In the table, this pole is grouped together with other secondary winding poles. Using TF information in subplot A and B, the primary and secondary pole contributions in the two-winding TF is determined and marked as shown in subplot D. As seen from the table, three more secondary zeros have realigned in such a fashion that they are now more closer to the secondary poles, causing increased pole-zero cancellations, viz. s1, s2, s3, and s4 can be treated as cancelled. These poles are seen as sharp kinks in the TF. This effectively reduces the number of secondary poles in the resultant $\mathrm{TF}$, implying that reduced information from secondary winding is available to the outside world. On the other hand, the trend for primary poles is opposite, wherein the pole-zero pairs show a tendency to separate out. For example, pole p3 that earlier had cancelled with its zero (distance between $\mathrm{p} 3$ pole and zero was $0.0069 \mathrm{i}$ ) is now beginning to emerge as a pole, as seen in subplot $\mathrm{D}$ (the distance between $\mathrm{p} 3$ pole and zero has increased to 0.044i). Also, it is seen that the height of the secondary poles in two-winding TF is greater in the short-circuited case, compared to the open-circuited case.

In summary, when $\alpha$ of the two windings is far different, the $\mathrm{TF}$ of the primary winding with the secondary open-circuited has effectively fewer poles, compared to the short-circuited case, thus implying that less information is being conveyed from it. These gross features are noticeable for all values of $\alpha_{p} \leq 3.0$.

\section{B. Case 2: $\alpha_{p} / \alpha_{s}=3.16 / 15$}

1) Secondary Short-Circuited: The results for case 2 are shown in Fig. 3 and Table III. The TF of the primary winding (subplot A) when considered alone has three distinct poles ( $\mathrm{p}$, p2, p3) and the fourth pole (p4) can be considered to have cancelled. The secondary has as before, four distinct poles (s1-s4, subplot B). The two-winding TF with secondary shorted is shown in subplot C Fig. 3. The pole contributions from the primary and secondary winding in the resultant TF have been marked as explained before and are shown. The relative distances between p1-p2, p2-p3, and p3-p4 in the two-winding $\mathrm{TF}$ are more or less similar to what it was in the single-winding TF. A similar thing is observed amongst the secondary poles as well. The distance rule is used to differentiate amongst s1 and p2 (i.e., whether the pole sequence in subplot $\mathrm{C}$ is $\mathrm{s} 1$ and $\mathrm{p} 2$, and not, $\mathrm{p} 2$ and $\mathrm{s} 1$ ). The primary pole $\mathrm{p} 4$ in the two-winding $\mathrm{TF}$ is clearly seen in contrast to the single-winding case, where
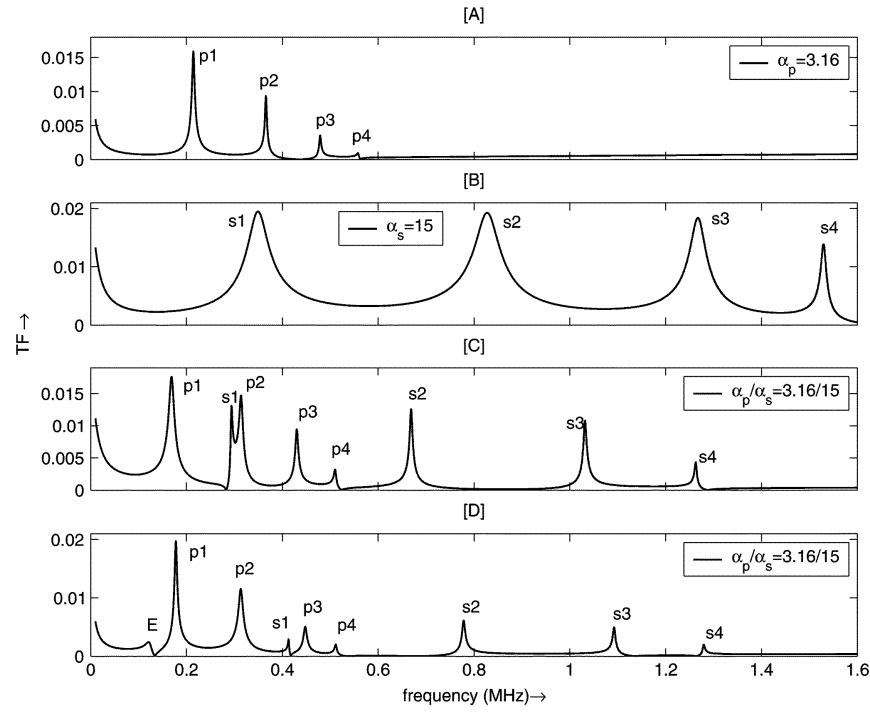

Fig. 3. TF from swept frequency analysis. Case 2: $\alpha_{p} / \alpha_{s}=3.16 / 15$. (a) Primary alone. (b) Secondary alone. (c) Two windings: Secondary shorted. (d) Secondary open.

TABLE III

Analytically Computed TF POles AND Zeros Case $2: \alpha_{p} / \alpha_{s}=3.16 / 15$ (Pole Zero Cancellations ARe Shown Shaded)

\begin{tabular}{|c|c|c|c|c|c|c|}
\hline & \multirow{2}{*}{\multicolumn{2}{|c|}{ Individual winding }} & \multicolumn{4}{|c|}{ Both the windings } \\
\hline & & & \multicolumn{2}{|c|}{ Secondary (Short) } & \multicolumn{2}{|c|}{ Secondary (Open) } \\
\hline & Poles & Zeros & Poles & Zeros & Poles & Zeros \\
\hline \multirow{7}{*}{ 蔦 } & .0024 & & & & -0.0024 & \\
\hline & \multirow{2}{*}{$\begin{array}{l}-0.0033 \\
\pm 1.3458 \mathrm{i}\end{array}$} & $\begin{array}{c}-0.9943 \\
\pm 1.2517 \mathrm{i} \\
\end{array}$ & \multirow{2}{*}{$\begin{array}{l}-0.0040 \\
\pm 1.0608 \mathrm{i}\end{array}$} & \multirow{2}{*}{\begin{tabular}{|c|c} 
& 1.3956 \\
$\pm 1.3671 \mathrm{i}$ \\
-1.4050 \\
$\pm 1.3687 \mathrm{i}$ \\
\end{tabular}} & \multirow{2}{*}{$\begin{array}{c}-0.0034 \\
\pm 1.1176 \mathrm{i}\end{array}$} & \multirow{2}{*}{$\begin{array}{c}-1.2119 \\
\pm 0.8432 \mathrm{i} \\
1.2083 \\
\pm 0.8457 \mathrm{i} \\
\end{array}$} \\
\hline & & $\begin{array}{c}0.9908 \\
\pm 1.2541 \mathrm{i} \\
\end{array}$ & & & & \\
\hline & $\begin{array}{l}-0.0061 \\
\pm 2.2980 \mathrm{i} \\
\end{array}$ & & -0.0065 & & $\begin{array}{c}-0.0064 \\
\pm 1.9673 \mathrm{i} \\
\end{array}$ & \\
\hline & \multirow{2}{*}{$\begin{array}{c}-0.0094 \\
\pm 3.0084 \mathrm{i}\end{array}$} & $\begin{array}{c}0.1436 \\
\pm 2.7561 \mathrm{i} \\
\end{array}$ & \multirow{2}{*}{$\begin{array}{l}-0.0094 \\
\pm 2.7011 \mathrm{i}\end{array}$} & $\begin{array}{c}-0.4987 \\
\pm 2.4162 \mathrm{i} \\
\end{array}$ & \multirow{2}{*}{$\begin{array}{c}-0.0077 \\
\pm 2.8130 \mathrm{i}\end{array}$} & $\begin{array}{c}-0.6955 \\
\pm 2.8028 \mathrm{i} \\
\end{array}$ \\
\hline & & $\begin{array}{c}-0.1437 \\
\pm 2.7568 \mathrm{i} \\
\end{array}$ & & $\begin{array}{c}0.4831 \\
\pm 2.4189 \mathrm{i} \\
\end{array}$ & & $\begin{array}{c}0.6798 \\
\pm 2.8102 \mathrm{i} \\
\end{array}$ \\
\hline & $\begin{array}{c}-0.0123 \\
\pm 3.5082 \mathrm{i} \\
\end{array}$ & $\begin{array}{c}-0.0103 \\
\pm 3.5387 \mathrm{i} \\
\end{array}$ & $\begin{array}{c}-0.0121 \\
\pm 3.2656 \mathrm{i} \\
\end{array}$ & $\begin{array}{c}-0.0121 \\
\pm 3.2898 \mathrm{i}\end{array}$ & $\begin{array}{c}-0.0120 \\
\pm 3.2131 \mathrm{i}\end{array}$ & $\begin{array}{c}-0.0127 \\
\pm 3.3637 \mathrm{i}\end{array}$ \\
\hline \multirow{8}{*}{ 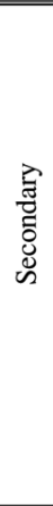 } & \multirow[t]{2}{*}{-0.0029} & $\begin{array}{c}-1.3795 \\
1.3782 \\
\end{array}$ & $\begin{array}{l}-0.0015 \\
-0.0109 \\
\end{array}$ & -0.0029 & $\begin{array}{c}-0.0052 \\
\pm 0.7764 \mathrm{i}\end{array}$ & $\begin{array}{c}-0.0045 \\
\pm 0.8414 \mathrm{i} \\
\end{array}$ \\
\hline & & $\begin{array}{l}-287.39 \\
287.382 \\
\end{array}$ & $\begin{array}{c}-0.0450 \\
\pm 1.8442 \mathrm{i} \\
\end{array}$ & $\begin{array}{c}-0.0029 \\
\pm 1.7781 \mathrm{i} \\
\end{array}$ & $\begin{array}{c}-0.0069 \\
\pm 2.5969 \mathrm{i} \\
\end{array}$ & $\begin{array}{r}-0.0050 \\
\pm 2.6243 \mathrm{i} \\
\end{array}$ \\
\hline & \multirow[b]{2}{*}{$\begin{array}{l}-0.0039 \\
\pm 2.1827 \mathrm{i}\end{array}$} & & \multirow{2}{*}{$\begin{array}{c}-0.0066 \\
\pm 4.1973 \mathrm{i}\end{array}$} & $\begin{array}{c}0.7615 \\
\pm 5.5172 \mathrm{i} \\
\end{array}$ & \multirow{2}{*}{$\begin{array}{c}-0.0068 \\
\pm 4.8838 \mathrm{i}\end{array}$} & \multirow{2}{*}{$\begin{array}{c}-0.0079 \\
\pm 4.3114 \mathrm{i}\end{array}$} \\
\hline & & & & $\begin{array}{c}0.7787 \\
\pm 5.5165 \mathrm{i} \\
\end{array}$ & & \\
\hline & $\begin{array}{c}-0.0067 \\
\pm 5.1776 \mathrm{i} \\
\end{array}$ & & $\begin{array}{c}-0.0930 \\
\pm 6.4778 \mathrm{i} \\
\end{array}$ & & $\begin{array}{c}-0.0093 \\
\pm 6.8624 \mathrm{i} \\
\end{array}$ & $\begin{array}{c}-0.0092 \\
\pm 7.1366 \mathrm{i} \\
\end{array}$ \\
\hline & \multirow{2}{*}{$\begin{array}{c}-0.0094 \\
\pm 7.9448 \mathrm{i}\end{array}$} & $\begin{array}{c}-4.6505 \\
\pm 7.0212 \mathrm{i} \\
\end{array}$ & \multirow{2}{*}{$\begin{array}{c}-0.0110 \\
\pm 7.9406 \mathrm{i}\end{array}$} & \multirow{2}{*}{$\begin{array}{c}-0.0110 \\
\pm 8.0953 \mathrm{i}\end{array}$} & \multirow{2}{*}{$\begin{array}{c}-0.0109 \\
\pm 8.0427 \mathrm{i}\end{array}$} & \multirow{2}{*}{$\begin{array}{c}-0.0110 \\
\pm 7.9478 \mathrm{i}\end{array}$} \\
\hline & & $\begin{array}{c}4.6194 \\
\pm 7.0454 \mathrm{i} \\
\end{array}$ & & & & \\
\hline & $\begin{array}{c}-0.0107 \\
\pm 9.6077 \mathrm{i}\end{array}$ & $\begin{array}{c}-0.0235 \\
\pm 10.808 \mathrm{i}\end{array}$ & & & & \\
\hline
\end{tabular}

it had cancelled. Further, it is now observed that all primary and secondary poles are clearly identifiable in the two-winding case (it can be seen in Table III that only one pole-zero pair has cancelled). In case 1, it was not so. The TF behavior concerning pole heights and separation distances is quite similar to that seen in Case 1. 

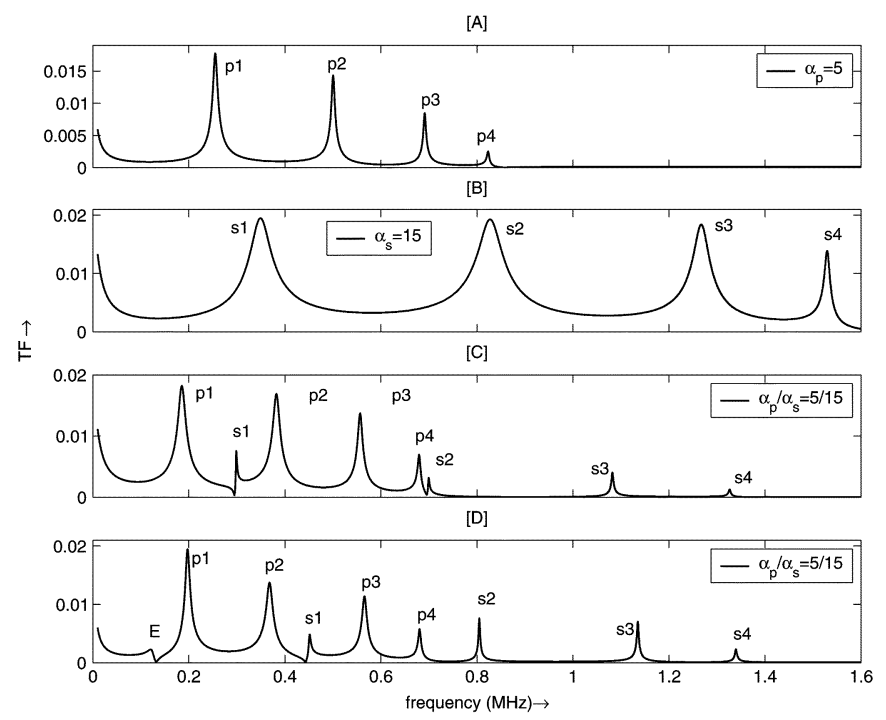

Fig. 4. TF from swept frequency analysis. Case 3: $\alpha_{p} / \alpha_{s}=5 / 15$. (a) Primary alone. (b) Secondary alone. (c) Two-windings: secondary shorted. (d) Secondary open.

The resultant TF in this case also bears characteristics that closely resemble a disc/layer type of winding rather than an interleaved winding. Further, starting from this value of $\alpha_{p}$ onwards, it is observed that, both open and short-circuited condition yield same quantum of information in terms of the number of distinctly observable two winding TF poles.

2) Secondary Open-Circuited: Subplot D in Fig. 3 shows the resultant TF. The extra pole is marked "E" as shown, and the remaining primary and secondary pole contributions are also labeled. The extra pole is easy to distinguish, as its shape remains constant throughout the simulation, and in almost all cases, it is the lowest frequency pole. The distance rule is used to differentiate between $\mathrm{s} 1$ and $\mathrm{p} 3$. It must be noted that pole s1 undergoes a right shift compared to the position it occupied in the single winding case, while the remaining secondary poles continue to shift left. In both the cases discussed so far, the secondary pole heights in two winding case is more in short-circuited case, compared to the open-circuited case.

In summary, with an increase in $\alpha_{p}$, it is seen that resultant two winding TF has same number of poles, for both secondary terminal conditions, but as pole heights are more in resultant TF when secondary is short circuited, it may be preferable to use the short-circuited secondary condition, as it will be relatively more sensitive and hence easier to detect changes.

\section{Case 3: $\alpha_{p} / \alpha_{s}=5 / 15$}

1) Secondary Short-Circuited: Fig. 4 depicts results for Case 3 . Here, all primary and secondary poles are clearly seen and there are no cancellations when windings are considered alone. Subplot $\mathrm{C}$ shows resultant TF with secondary short-circuited and the pole contributions marked. The distance rule is used to distinguish between $\mathrm{p} 4$ and s2, while the rest are easily identifiable due to the similarity in shape and trend being followed with increase in $\alpha_{p}$. Also, poles s1 and s2 are pretty close to their corresponding zeros, as can be made out from

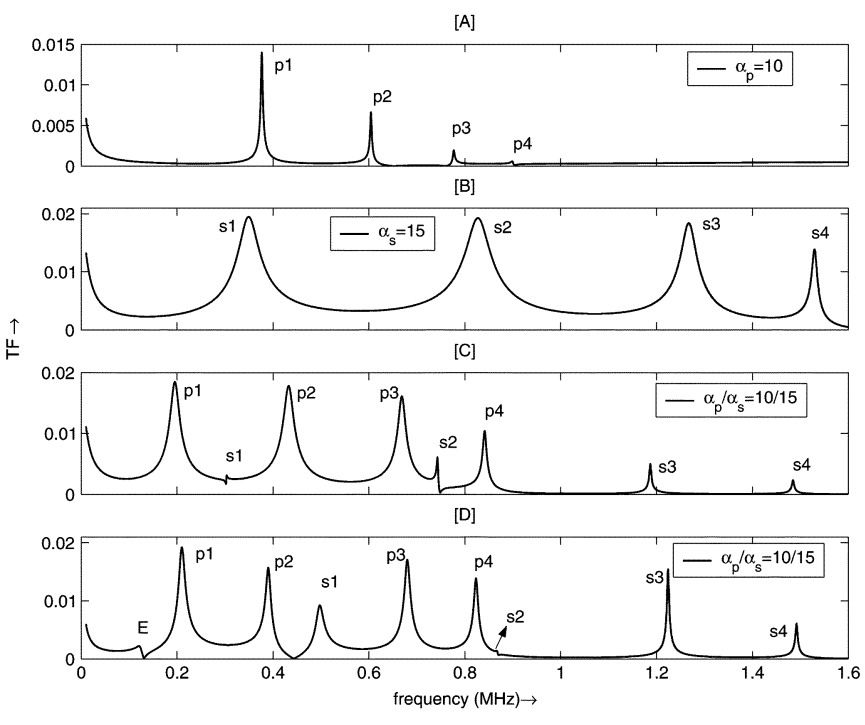

Fig. 5. $\quad \mathrm{TF}$ from swept frequency analysis. Case 4: $\alpha_{p} / \alpha_{s}=10 / 15$ (a) Primary alone, (b) secondary alone, (c) two windings: secondary shorted, (d) secondary open.

the numerical values. Most features observed in earlier cases are also seen here. One conspicuous feature observed is that, for a range of $\alpha_{p}$ values between 4.5 and 7.5, all other things remaining unchanged, only the secondary pole heights in the two winding TF begins to decrease and attain a minimum somewhere around $\alpha_{p}=7.0$ (secondary poles, although present, have very small amplitudes and, hence, are not seen in TF).

2) Secondary Open-Circuited: Subplot D shows the TF for open circuited secondary. The extra pole "E" is marked, and the rest of the poles are labeled as discussed already. Here, the distance rule seems to be not met in the strict sense (i.e., distance p2-p3 in subplot D is not less than distance p1-p2, as it should have been). So using the trend in previous cases, the pole contributions from the two windings are marked, but for this minor discrepancy, all other features seen in earlier cases are also observed here, and the subplot D is self-explanatory.

\section{Case 4: $\alpha_{p} / \alpha_{s}=10 / 15$}

1) Secondary Short-Circuited: The results are shown in subplot A, B, and C of Fig. 5. As mentioned in the previous case, for values of $\alpha_{p}$ greater than 7.5, the secondary pole contributions begin to reappear in the resultant TF (compare subplots $C$ in Figs. 4 and 5) with considerable amplitude. The other poles are labeled as explained earlier. Numerical values when examined reveal that pole s1 in two winding case has cancelled, while s2 is close to cancellation, and these are seen as sharp kinks in the TF, in subplot $\mathrm{C}$. The rest of the poles are distinctly visible.

2) Secondary Open-Circuited: The TF for this case is shown in subplot D. The extra pole "E" is marked and is distinctly different from the remaining poles. Here again, the distance rule is not met as far as poles p1, p2, and p3 are concerned, but going by an emerging trend as $\alpha_{p}$ increases, it is easy to identify the poles and winding to which they belong to. The remaining poles are also labeled as earlier. Pole s2 

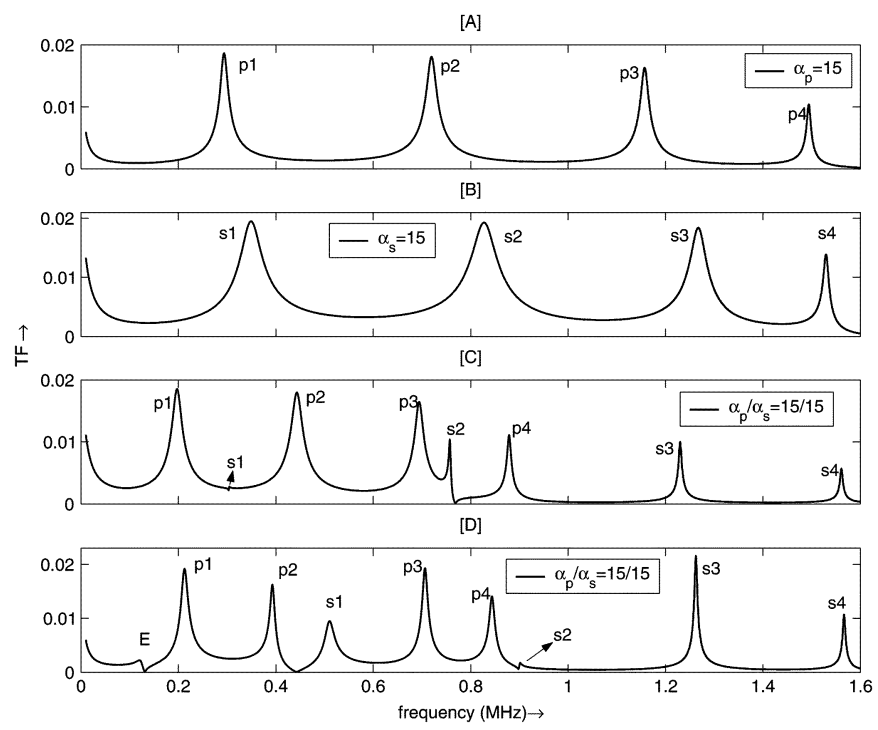

Fig. 6. TF from swept frequency analysis. Case 5: $\alpha_{p} / \alpha_{s}=15 / 15$ (a) Primary alone, (b) secondary alone, (c) two windings: secondary shorted, (d) secondary open.

has cancelled and, hence, appears as a tiny kink in subplot D. Another aspect to be noted for values of $\alpha_{p}$ beyond 10 is that, except pole s1, which undergoes a right shift, the other secondary poles $\mathrm{s} 2$ to $\mathrm{s} 4$ practically remain at the same frequency position, compared to its position in the single winding case (compare the position of s2, s3, and s4 in subplots D and B).

\section{E. Case 5: $\alpha_{p} / \alpha_{s}=15 / 15$}

1) Secondary Short-Circuited: Fig. 6 shows the results for this case. Both the windings are of similar type, and so it will be interesting to investigate this case. Usually, this type of condition with both windings having very nearly the same $\alpha$ values is encountered in medium voltage transformers. Subplot $\mathrm{C}$ shows the resultant TF for the short-circuited case, with pole contributions labeled as shown. Except for pole s1, the rest are distinctly seen. It now becomes amply clear that as the value of $\alpha_{p}$ equals $\alpha_{s}$, the distance rule for poles $\mathrm{p} 1, \mathrm{p} 2$, and $\mathrm{p} 3$ is not obeyed (to a smaller extent in the short-circuited case and to greater extent in open-circuited case). This minor discrepancy does not affect the task of identification of the poles and the pertinent windings to which they belong to, as is evident in this case. As already mentioned, once the trend of pole shifts is established, such a discrepancy can be overcome. When the two windings are of disk/layer type, the resultant TF contains pole contributions from both windings and possesses an overall character that is quite similar to disk winding.

2) Secondary Open Circuited: Subplot D shows the results for this condition with all poles labeled. Except for pole s2, the remaining poles are detectable. The position of extra pole "E" is almost the same in all of the five case. Also, its peculiar shape and amplitude aids in its identification. Most features observed in earlier cases are also seen here. The fact mentioned about distance rule can be verified here. As mentioned earlier, when $\alpha$ values of primary and secondary are nearly the same, or are equal, the TF for both terminal conditions of secondary are not very different. So there is no additional advantage to be derived due to the terminal configuration in such cases.

\section{F. Case 6: Primary Is Disc/Layer and Secondary Is Interleaved}

Next, it was also important to analyze a situation wherein the primary is a disc/layer winding and secondary is interleaved. Such a condition can arise when the LV winding of a large HV transformer is to be impulse tested. Therefore, keeping $\alpha_{p}$ constant at $15, \alpha_{s}$ was gradually varied from 1.414 to 5 , and both conditions of secondary winding (short and open) were considered. The results were analyzed in exactly the same way as in the previous cases. The following points emerge from these simulations (for detailed analysis, see [11]).

- In general, observations made in the previous five cases were found in these studies as well. Pole contributions from the two windings were identifiable in a manner similar to what has already been explained.

- For lower values of $\alpha_{s}$, the resultant TF has only primary winding poles, as all secondary pole-zero pairs almost cancel out. So correlating poles and windings to which they belong to become simple. But as $\alpha_{s}$ increases, the contribution from secondary windings begins to emerge and then increases with it.

- For minor variations, both terminal conditions of the secondary winding result in similar TF, as far as the number of poles is concerned (i.e., both TF reveal more or less similar information).

The overall summary arising from simulations is enumerated below.

$\sqrt{ } \quad$ Given the TF of the primary and secondary windings considered in isolation and the pole zero values of the two-winding transformer, the extent of interaction between the windings and the role played by each factor in shaping the resultant TF can be individually determined.

$\sqrt{ } \quad$ Interaction between the windings can be systematically analyzed by the proposed method, and this can finally lead to the identification of all poles in the resultant $\mathrm{TF}$ and the associated winding in a two-winding transformer.

$\sqrt{ } \quad$ It is observed that the contribution from the secondary winding need not always be present in the resultant $\mathrm{TF}$, and this aspect greatly depends not only on the type of windings involved but on the relative values of their circuit parameters and terminal conditions as well. Hence, it is not possible to arrive at generalized statements to convey the observations.

$\sqrt{ }$ However, it is believed that by adopting this proposal on actual transformer windings, valuable practical data can be gathered for all types of windings used and different terminal conditions. Then, based on these data, guidelines for TF interpretation can be formulated only for specific and commonly encountered $\alpha_{p}$ and $\alpha_{s}$ conditions. 


\section{EXPERIMENTAL RESULTS}

Experiments were carried out to verify simulation results. A simple two-winding transformer was required, and so, the model used consisted of two concentric and snugly fitting air-cored coils. The primary was wound on an insulating former of diameter $21 \mathrm{~cm}$, using a 24 SWG-enamelled copper wire with 20 turns per section (single layer), and ten such sections were used. Similarly, the secondary was wound on an insulating form of diameter $16.5 \mathrm{~cm}$ using 20 SWG-enamelled copper wire with 15 turns per section (single layer), and ten such sections were used. Both windings had almost the same height. All self and mutual inductances were measured with an L-C-R bridge (see Table I). As it is not easy to achieve any desired value of series and shunt capacitance in such model coils, lumped capacitances were externally connected to each section to exactly match the conditions of the equivalent circuit in Fig. 1. The primary and secondary windings have a shunt capacitance of 560- and 1020-pF/section, respectively. The series capacitance of secondary is kept fixed at $350 \mathrm{pF} /$ section (corresponding to $\alpha_{s}=16$ ). Five different values of series capacitance for primary were chosen, viz. $20,10.2,4.7,2.2$, and $0.56 \mathrm{nF}$ per section corresponding to five values of $\alpha_{p}$, namely, 1.673, 2.36, 3.45, 5.0, and 10.0, respectively.

The experiments consisted of determining TF using both time- and frequency-domain approaches. As in simulation studies, the individual windings were initially tested alone, and later, the secondary was placed inside the primary, and experiments were repeated for the two-winding case, for shortand open-circuited secondary condition. In the time-domain approach, using a low-voltage RSG (Haefely RSG 482), data $(128 \mathrm{~K}$ points, sampled at $10 \mathrm{~ns})$ of lightning impulse voltage and neutral current (voltage across $47 \Omega$ ) were acquired (using a SONY Tektronix RTD-710A digitizer, 10 b, $200 \mathrm{MS} / \mathrm{s}$ ), from which the TF was computed [via fast Fourier transform (FFT)]. The TF was also measured directly in frequency domain by the swept frequency method (using a computer-controlled sine generator, AGILENT AWG-33 250A and RTD-710A, programmed in VEE Pro environment). While discussing each result, the corresponding ten-section simulation results are also given to facilitate a horizontal comparison. The measured values of all components were used during simulations. Loss was modeled as 1.2 and $0.5 \Omega$ per section (measured) for the two windings, respectively. Only a few typical results are presented here (for details, see [11]).

Finally, it must be mentioned that these experiments with model coils are meant to only verify gross aspects predicted in simulations. The frequency limit of such lumped parameter tabletop models is only about $0.8 \mathrm{MHz}$. Also, pole attenuation at higher frequencies has not adequately been modeled in simulations (considered only as a constant). Hence, in all fairness, minor aspects of two-winding TF discussed in simulation cannot be expected to be reproduced here. Last, it is seen that estimated pole frequencies by simulation and that actually measured in practice, begin to deviate beyond the limit of $0.8 \mathrm{MHz}$. This is not an error but a limitation of the model. Despite this deviation in estimated and measured frequencies, the proposed method is applicable, as will be demonstrated.
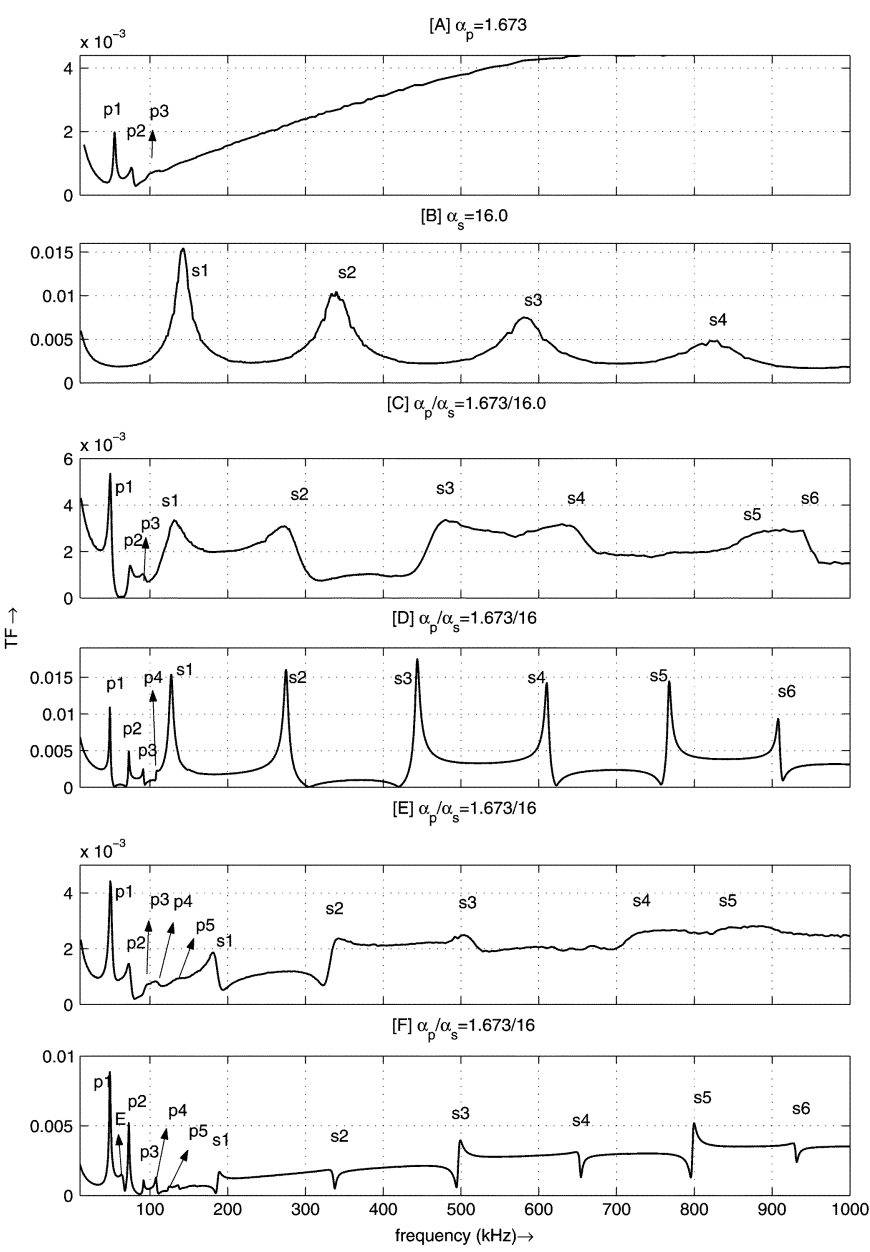

Fig. 7. TF from swept frequency measurements $\left(\alpha_{p} / \alpha_{s}=1.673 / 16\right)$ (a) Primary alone. (b) Secondary alone. (c) Two windings: secondary shorted. (d) PSPICE results for (c). (e) Two-windings: secondary open. (f) PSPICE results for (e).

\section{A. Case 7: Measurement by Swept Frequency or FRA Method}

1) $\alpha_{p} / \alpha_{s}=1.673 / 16.0$ : The measured $\mathrm{TF}$ for the two windings, each considered in isolation, is shown in subplots A and B of Fig. 7. The primary and secondary poles are marked as shown. The interleaved and disc/layer winding characteristics described in Section II are clearly evident. In subplot B, beyond $1 \mathrm{MHz}$, the detection of poles was increasingly difficult, despite employing averaging during waveform acquisition. Measured TF for the two-winding case for secondary short-circuited is shown in subplot $\mathrm{C}$ with pole contributions marked and the corresponding simulation result shown in subplot $\mathrm{D}$. The overall match between experimental and simulated TF is good at lower frequencies, while it is considered satisfactory at higher frequencies (ignoring frequency mismatch). Another point to be mentioned is that somehow the match between measured and simulated TF in the trough region between poles $\mathrm{s} 1-\mathrm{s} 2, \mathrm{~s} 2-\mathrm{s} 3$, etc. in subplot $\mathrm{C}$ and $\mathrm{D}$ is not good. Although pole amplitudes are well detected here, the TF magnitude does not decay as much as predicted.

The contribution from individual windings can easily be identified following the proposed method. Identification of pole contributions from windings is first carried out for the simulated case, and thereafter, repeated for the measured TF. All salient features predicted in the simulation studies (Case 1) are nicely 
reproduced in this experiment (e.g., in the subplot $\mathrm{C}$, poles $\mathrm{p} 1$, $\mathrm{p} 2$, etc. and s1, s2, etc., shift left compared to their position in subplot B). Also, primary winding poles in two-winding TF (subplot $\mathrm{C}$ ) have a higher amplitude compared to the value when primary is considered alone (subplot A). Likewise, most features described in Case 1 can be cross verified.

Subplots $\mathrm{E}$ and $\mathrm{F}$ correspond to the two-winding TF when the secondary is open-circuited. The poles in the two-winding TF have been labeled as shown. It is observed that the match between subplots $\mathrm{E}$ and $\mathrm{F}$ is very good up to about $800 \mathrm{kHz}$. For this very low value of $\alpha_{p}$, simulation results also show that the extra pole " $E$ " is almost buried and undetectable, as is the case in subplot E. It was observed that when $\alpha_{p}$ is reduced below a certain value, in this case to about 1.7, the position of extra pole "E" undergoes a right shift and lies in between poles $\mathrm{p} 1$ and $\mathrm{p} 2$, and it is very difficult to identify it from the TF plot. Numerical values show its presence. Apart from this, the remaining poles are easily identifiable. Also, the characteristic slope of TF in the higher frequency regions is well reproduced in subplot $\mathrm{E}$ compared to that in subplot F. Last, finer aspects of TF are nicely made out in zoomed plots.

Finally, as predicted during simulation (Case 1), in such cases, two-winding TF contains contributions from both primary and secondary. This has been verified by this experiment.

2) $\alpha_{p} / \alpha_{s}=10.0 / 16.0$ : Results for this case are shown in the different subplots of Fig. 8, following the same format as in previous case. Comparison of subplots $\mathrm{C}$ and $\mathrm{D}$ shows that the match is very good until about $800 \mathrm{kHz}$, and one without difficulty can identify all poles up to 7 in the measured results. For obvious reasons, s2, s3, s4, and s5 are not easy to detect, as is evident from simulation results shown in subplot D. Numerical values assist in such cases to determine whether a pole would be seen in the TF or not. The poles s6 and s7 are barely visible and marked as shown in subplot $\mathrm{C}$. The minor kinks predicted in simulation are, in general, difficult to capture, even with the swept frequency method (with data averaging), since the change in TF to be detected is very small; it further gets swamped due to the close proximity of neighboring poles or a higher TF value at that frequency.

The measured TF for secondary open circuited is shown in subplot $\mathrm{E}$ and the simulated result in subplot $\mathrm{F}$. In subplot $\mathrm{E}$, despite its low amplitude, the extra pole "E" can still be detected and is marked (when the TF is zoomed, it is nicely seen). The remaining poles are labeled. Here, apart from pole $\mathrm{s} 1$, the remaining secondary poles are barely visible. A few of them have been identified using zoomed plots and are as shown. The overall match between subplots $\mathrm{E}$ and $\mathrm{F}$ is very good, thus proving that the model used for the studies was reasonably accurate. The cross verification of the simulation results by experiments implies that the proposed method is, to that extent, practicable. The overall results of this case are in consonance with what was predicted in simulation. Very similar results have been obtained for the other $\alpha_{p}$ values considered, and for details see [11].

\section{B. Case 8: Measurement by Time Domain or LVI Method}

Measurements were also made by the time-domain approach for all cases considered in the swept frequency experiments. One single advantage in favor of this approach is that the time
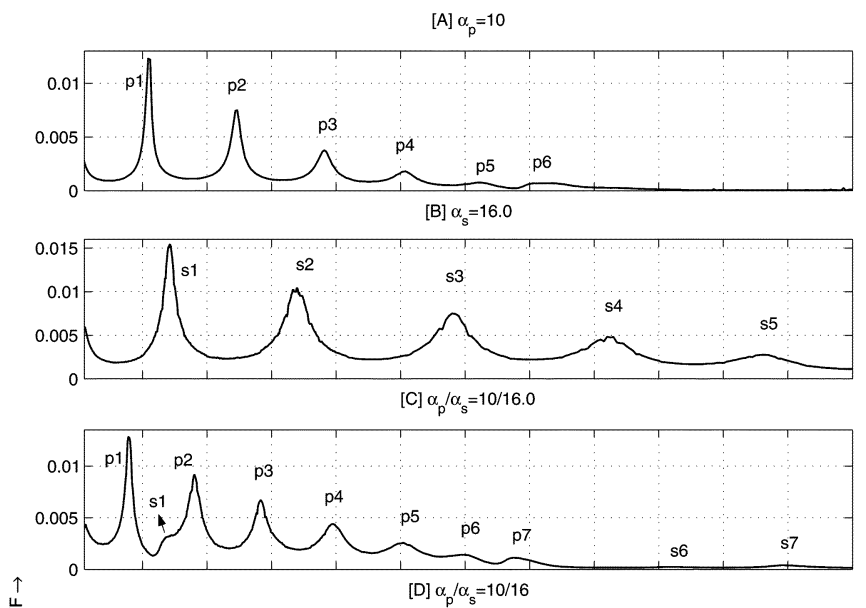

$\stackrel{\uparrow}{*}$
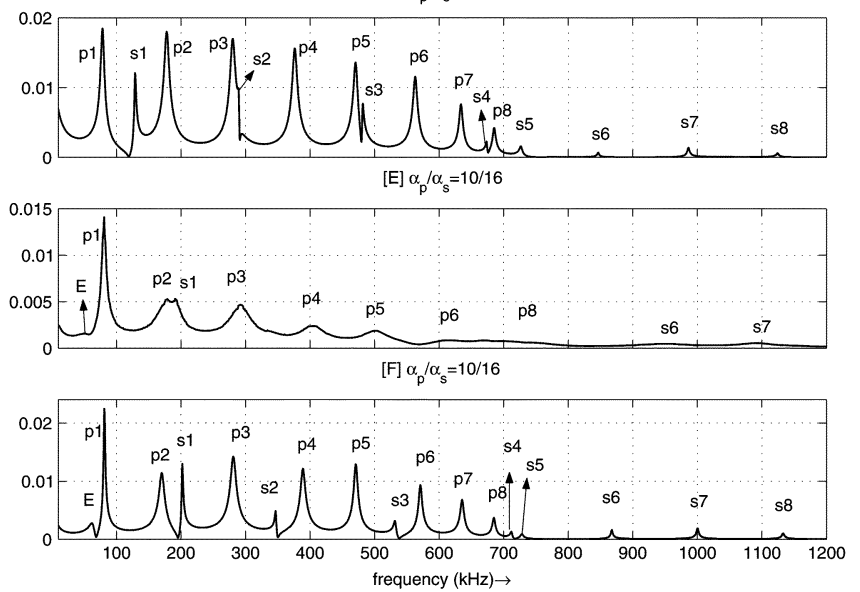

Fig. 8. TF from swept frequency measurements $\left(\alpha_{p} / \alpha_{s}=10 / 16\right)$. (a) Primary alone. (b) Secondary alone. (c) Two windings: secondary shorted. (d) PSPICE results for (c). (e) Two-windings: secondary open. (f) PSPICE results for (e).

taken to perform the test is almost negligible, whereas it can take hours in the swept frequency method. In all of these experiments, great care was taken to ensure that almost $95 \%$ full-scale deflection of each channel was used while recording data. Also, in all cases, both the voltage and neutral current waveforms reach very close to zero values when about a $32 \mathrm{~K}$ long record is considered. So no additional windowing or preprocessing was employed while determining the TF. The TF was computed directly from the data gathered as a ratio of spectra of neutral current and spectra of input impulse voltage.

As an example, results for $\alpha_{p} / \alpha_{s}=5.0 / 16$ are given in Fig. 9, along with swept frequency results. In Fig. 9, subplots A and B give results from the LVI method and swept frequency method, respectively, for secondary short-circuited condition. Similarly, subplots C and D are the results for the secondary open-circuited condition. This check with LVI is essential in order to verify that experiments are repeatable and whether all of the detected poles are only due to a phenomenon in the test setup and not extraneous in origin. On this count, it must be mentioned that an excellent match has been obtained between the results predicted by the time-domain method and that from the swept frequency method.

The TF poles in each subplot have been labeled as explained already. A comparison of the subplots A with B and C with D 


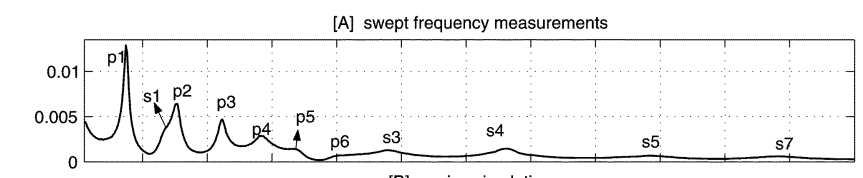

[B] pspice simulation
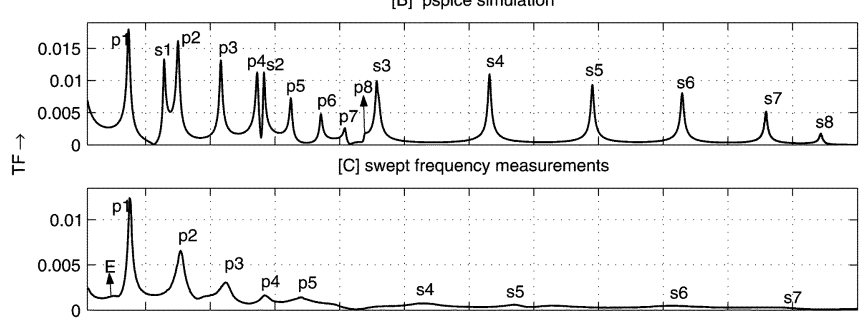

[D] pspice simulation

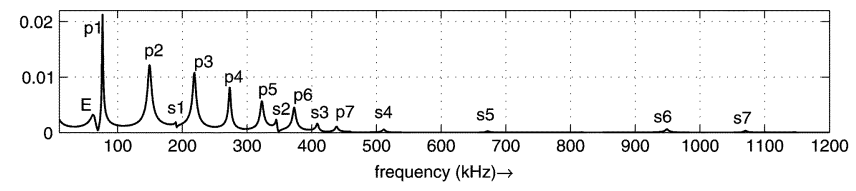

Fig. 9. $\mathrm{TF}$ from time-domain $[\mathrm{A}, \mathrm{C}]$ and frequency-domain $[\mathrm{B}, \mathrm{D}]$ measurements $\alpha_{p} / \alpha_{s}=5.0 / 16.0$.

shows that the match is very good. As expected, the TF measured by the time-domain method becomes noisy as frequency increases. In practical situations, these conditions can mask low amplitude poles from being detected or spotted. For example, in subplot A, poles $\mathrm{p} 8$ and $\mathrm{s} 5$ cannot automatically be detected without the help of simulation results (subplot B). Further, since in the swept frequency method the SNR is very good, the TF measured can be plotted in logarithmic scale, and in this way, very low amplitude poles can still be detected. Using this, in subplot D, s4, s5, s6, s7, and s8 were found. The close agreement of TF obtained from the two methods implies the following.

- The measurements were accurate and repeatable.

- They validate and show the practical viability of the proposed method.

\section{DISCUSSION}

The factors that influence the TF of a two-winding transformer were studied in some detail. The following are some thoughts for future study.

1) As a consequence of the study, it emerges that for ensuring a correct assessment of the TF, it is essential to include along with measured TF, information relating to 1) types of all windings involved and their $\alpha$ value, 2) exact test conditions, 3) circuit parameters as per equivalent circuit in Fig. 1, and 4) preprocessing, if any, in case the TF is determined from time-domain data. Availability of this information will enable the assessment of the interaction and to determine which among them are more significant enough to have a bearing on the resultant TF.

2) The above point logically implies that the study has to first of all be extended to consider the presence of multiple windings. Such a situation is easy to visualize in three-phase transformers. For achieving this, it is essential that parameters of equivalent circuit of each winding, and all interwinding capacitances, must be known. Such a study can be used to determine under what conditions the interaction of neighboring windings can be neglected.
The rationale for this argument is that the TF of even a three-phase transformer does not have more than six to seven significant frequencies in its TF, which means that although multiple windings are present and its interactions exist, the observed number of natural frequencies or poles is not a linear function of the number of windings. Hence, it will be interesting to determine which of the multiple windings and interactions can, in practice, be ignored during assessing TF.

3) One factor that has not been considered and might have an effect on the results is the influence of the iron core. This factor, if considered, is expected to have some bearing on the results, especially when one of the windings is interleaved. This is because interleaved winding, by itself, has only a few very low-frequency poles [10], and the effect of iron is usually significant at the lower frequencies. So some additional changes in low-frequency poles can be expected. Therefore, it will be interesting to see how this factor would matter in the final analysis.

\section{CONCLUSION}

The paper provides quantitative evidence, for the first time, about how actually the resultant TF of a two-winding transformer originates. Almost all important factors and interactions that influence it have been identified and studied. It was further demonstrated that not only are the type of windings involved important but their relative $\alpha$ values are also equally important.

Additionally, it was demonstrated how the TF of a two-winding transformer could be interpreted from the knowledge of the TF of each winding considered in isolation. The ability to relate the TF poles of a two-winding transformer and the winding associated with it is a novel and original contribution. This aspect has been experimentally verified. It is believed that this information could be useful in fault location.

The close agreement of TF obtained from simulations, analytical calculations, and experiments for the two-winding transformer considered is sufficient validation not only of the correctness of the proposed method but also about its practical viability. In final conclusion, it is strongly believed that the findings of this paper open up newer avenues for pursuing research in analysis and interpretation of TF.

\section{ACKNOWLEDGMENT}

The authors thank Prof. B. I. Gururaj for his critical evaluation of this work and useful suggestions during the preparation of the manuscript. The second author expresses his sincere thanks to his research colleagues, K. Ragavan, for the programming help, and to V. Santosh, for lending him the VEE Pro program.

\section{REFERENCES}

[1] R. Malewski and B. Poulin, "Digital monitoring techniques for high voltage impulse tests," IEEE Trans. Power App. Syst., vol. PAS-104, pp. 3108-3114, Nov. 1985.

[2] - "Impulse testing of power transformers using the transfer function method," IEEE Trans. Power Delivery, vol. 3, pp. 476-489, Apr. 1988.

[3] T. Leibfried and K. Feser, "Monitoring of power transformers using the transfer function method," IEEE Trans. Power Delivery, vol. 14, pp. 1333-1341, Oct. 1999. 
[4] — , "Off-line and on-line monitoring of power transformers using the transfer function method," in Proc. IEEE Int. Conf. Electrical Insulation, Montreal, QC, Canada, June 1996, pp. 34-37.

[5] P. T. M. Vaessen and E. Hanique, "A new frequency response method for power transformers,” IEEE Trans. Power Delivery, vol. 7, pp. 384-391, Apr. 1992.

[6] M.-L. Pykala, V. Palva, J. Hallstrom, M. Aro, and L. Satish, "Transfer Function of Power Transformer-Part IV: Additional Measurements on Test Winding," Helsinki Univ. Technol., High Voltage Institute, Espoo, Finland, Tech. Rep., TKK-Sjt-36, 1999.

[7] P. A. Abetti, "Correlation of forced and free oscillations of coils and windings," in Trans. AIEE, vol. 78, Dec. 1959, pp. 986-996.

[8] P. A. Abetti, G. E. Adams, and F. J. Maginniss, "Oscillations of coupled windings," in Trans. AIEE, vol. 74, Apr. 1955, pp. 12-20.

[9] T. Leibfried, "EinfluB von Windungsschlussen auf die Ubertragungsfunktion von Transformator wicklungen am Beispiel homogener Spulen," Elect. Eng., pp. 99-108, Oct. 1997.

[10] L. Satish and A. Jain, "Structure of transfer function of transformers with special reference to interleaved windings," IEEE Trans. Power Delivery, vol. 17, pp. 754-760, July 2002.

[11] S. K. Sahoo, "An effort to understand what factors affect the transfer function structure of a two-winding transformer," M.Sc. thesis, Dept H. V. Engg., I.I.Sc., Aug. 2003.
L. Satish (SM'02) was born in 1964. He received the Ph.D. degree from the Indian Institute of Science (I.I.Sc.), Bangalore, India, in 1993.

Since 2001, he has been an Associate Professor with the Department of High Voltage Engineering, I.I.Sc. He was a Postdoctoral Fellow with ETH, Zurich, Switzerland, from 1993 to 1995 . He was a Visiting Researcher with H.V. Institute, Helsinki University of Technolology, Helsinki, Finland, during the summer of 1998. His research interests include application of signal processing to highvoltage impulse testing, diagnostics and condition monitoring, PD measurements, and pattern recognition.

Dr. Satish is a member of TF 1.1 in CIGRE WG D1-33.

Subrat K. Sahoo (S'04) was born in 1979. He received the B.E. degree (Hons.) in electrical engineering from the Indira Gandhi Institute of Technology, Sarang, India, which is affiliated with Utkal University, Orissa, India, in 2001. He recently submitted his thesis in engineering with the Department of High Voltage Engineering, Indian Institute of Science (I.I.Sc.), Bangalore, India. He is currently registered for the Ph.D. degree in the Department of High Voltage Engineering.

His research interests include diagnostics and monitoring of transformers. 